\title{
openheart Systematic oral hydration with water is similar to parenteral hydration for prevention of contrast-induced nephropathy: an updated meta-analysis of randomised clinical data
}

Shiv Kumar Agarwal, ${ }^{1}$ Sameh Mohareb, ${ }^{2}$ Achint Patel, ${ }^{3}$ Rabi Yacoub, ${ }^{4}$ James J DiNicolantonio, ${ }^{5}$ Ioannis Konstantinidis, ${ }^{6}$ Ambarish Pathak, ${ }^{7}$ Shailesh Fnu, ${ }^{1}$ Narender Annapureddy, ${ }^{8}$ Priya K Simoes, ${ }^{9}$ Sunil Kamat, ${ }^{10}$ Georges El-Hayek, ${ }^{9}$ Ravi Prasad, ${ }^{2}$ Damodar Kumbala, ${ }^{11}$ Rhanderson M Nascimento, ${ }^{12}$ John P Reilly, ${ }^{2}$ Girish N Nadkarni, ${ }^{4}$ Alexandre M Benjo ${ }^{2}$

To cite: Agarwal SK, Mohareb S, Patel A, et al. Systematic oral hydration with water is similar to parenteral hydration for prevention of contrastinduced nephropathy: an updated meta-analysis of randomised clinical data. Open Heart 2015;2:e000317. doi:10.1136/openhrt-2015000317

- Additional material is available. To view please visit the journal (http://dx.doi.org/ 10.1136/openhrt-2015000317)

Received 6 July 2015

Revised 2 September 2015 Accepted 8 September 2015

CrossMark

For numbered affiliations see end of article.

Correspondence to Dr Shiv Kumar Agarwal; drshivkumar.agarwal@gmail. com

\section{ABSTRACT}

Background: Contrast-induced nephropathy (CIN) is the third most common cause of hospital-acquired kidney injury and is related to increased long-term morbidity and mortality. Adequate intravenous (IV) hydration has been demonstrated to lessen its occurrence. Oral (PO) hydration with water is inexpensive and readily available but its role for CIN prevention is yet to be determined.

Methods: PubMed, EMBASE and the Cochrane Central register of controlled trials (CENTRAL) databases were searched until April 2015 and studies were selected using the Preferred Reporting Items for Systematic Reviews and Meta-Analyses (PRISMA) checklist. All randomised clinical trials with head-to-head comparison between PO and IV hydration were included.

Results: A total of 5 studies with 477 patients were included in the analysis, 255 of those receiving PO water. The incidence of CIN was statistically similar in the IV and PO arms $(7.7 \%$ and $8.2 \%$, respectively; relative risk $0.97 ; 95 \% \mathrm{Cl} 0.36$ to $2.94 ; \mathrm{p}=0.95)$. The incidence of CIN was statistically similar in the IV and PO arms in patients with chronic kidney disease and with normal renal function. Rise in creatinine at 48$72 \mathrm{~h}$ was lower in the P0 hydration group compared with IV hydration (pooled standard mean difference $0.04 ; 95 \% \mathrm{Cl} 0.03$ to $0.06 ; p<0.001 ;\left.\right|^{2}=62 \%$ ).

Conclusions: Our meta-analysis shows that systematic PO hydration with water is at least as effective as IV hydration with saline to prevent CIN. PO hydration is cheaper and more easily administered than IV hydration, thus making it more attractive and just as effective.

\section{INTRODUCTION}

Contrast-induced nephropathy (CIN) is a common cause of acute kidney injury (AKI)

\section{KEY QUESTIONS}

What is already known about this subject?

- There is conflicting evidence about the role of oral versus intravenous (IV) hydration in prevention of contrast-induced nephropathy along with a recent large randomised controlled trial showing equal efficacy with the two modalities.

What does this study add?

- This study adds to the available literature on oral versus IV hydration for prevention of contrast-induced nephropathy as well as evaluates a novel outcome in terms of change in serum creatinine in oral versus IV hydration.

How might this impact on clinical practice?

- Our meta-analysis supports that systematic oral hydration with water is as efficacious as IV hydration with saline to prevent contrast-induced nephropathy both in patients with and without chronic kidney disease. Oral hydration is cheaper and more easily administered than IV hydration, thus making it more attractive and just as effective.

and can constitute up to $10 \%$ of hospital-acquired AKI. ${ }^{1}$ CIN is defined as AKI after parenteral administration on radiocontrast agents in the absence of other causes. It has been associated with increased length of stay, mortality and increased healthcare costs. $^{2}{ }^{3}$ Optimal volume repletion has been considered to be protective against development of CIN and prophylactic hydration has been recommended in high-risk patients. ${ }^{4}$ Trivedi et a $\bar{\varphi}$ initially showed that intravenous (IV) fluid administration is 
superior to oral $(\mathrm{PO})$ hydration in reducing the incidence of CIN. However, subsequent studies showed no such difference in the incidence of CIN with either IV or PO hydration. ${ }^{6-8}$ Two meta-analyses by Cheungpasitporn et at and Hiremath $e t a l^{10}$ showed no such difference in the incidence of CIN. One large randomised controlled trial (RCT) has been recently published. ${ }^{11}$ In order to synthesise the newly available literature and to assess the impact of incorporating newer data, we performed an updated systematic review and quantitative meta-analysis of RCTs to assess the efficacy of PO hydration compared with IV hydration for CIN prevention.

\section{MATERIALS AND METHODS \\ Study selection}

This meta-analysis was designed in accordance with the principles set by the Preferred Reporting Items for Systematic Reviews and Meta-Analyses (PRISMA) checklist. ${ }^{12}$ We conducted a comprehensive literature search in MEDLINE, PubMed, EMBASE and the Cochrane Central register of controlled trials (CENTRAL), using the terms "oral" "intravenous" "hydration" and "contrast induced nephropathy." There were no limitations applied for the search criteria. References from original and review articles were hand-searched for additional studies.

Two authors (SKA and GNN) independently reviewed all identified publications and abstracts for analysis based on predetermined inclusion criteria. These inclusion criteria were (1) randomised clinical trials; (2) head-to-head comparison between PO and IV hydration; (3) outcomes of interest included development of CIN or change in creatinine and (4) no additional treatments in either arm. Studies were retrieved and references were reviewed using the title and abstract for their relevance. After the initial screening step, studies that met the inclusion criteria were retrieved in full and included in the analysis if they met the inclusion criteria. Conflicts were resolved by consensus and the help of a third reviewer (AMB).

The primary outcome of the study was to determine the efficacy of PO hydration in preventing CIN in comparison to IV hydration. Secondary outcomes included changes in creatinine at $48-72 \mathrm{~h}$ of contrast exposure and the requirement for renal replacement therapy.

\section{Data extraction}

Information regarding study characteristics, demographics, publication year, patient characteristics, type of procedure, contrast type and volume, PO and IV hydration regimen, and clinical outcomes including CIN and creatinine level after $48-72 \mathrm{~h}$ of the index procedure was recorded in a standardised Microsoft Excel sheet. We also collected information on the randomisation method, allocation concealment and blinding.

\section{Assessment of study quality}

Two authors (SKA and IK) independently assessed the quality and the risk of bias of the included trials with the Cochrane collaboration tool for the risk of bias. ${ }^{13}$ The summary of the risk of bias assessment is presented in figure 1. Analysis of the funnel plot revealed no significant publication bias (figure 2).

\section{Statistical analysis}

We used relative risk (RR) and risk difference (RD) with 95\% CIs as the metric of choice for categorical outcomes and continuous outcomes (rise in serum creatinine) were evaluated using standardised mean difference. Categorical variables were reported as percentages and continuous variables as mean $\pm \mathrm{SD}$. Weighted means were used for the pooled estimates of continuous variables. To assess heterogeneity across trials, we used the $\mathrm{I}^{2}$ statistic as proposed by Higgins and Thompson. ${ }^{14}$ Based on the $\mathrm{I}^{2}$ statistic, values of $25 \%, 50 \%$ and $75 \%$ were considered as yielding low, moderate and high heterogeneity, respectively. ${ }^{14}{ }^{15}$ Results were considered statistically significant at $\mathrm{p}<0.05$. A funnel plot and the adjusted rank correlation test were used to assess for publication bias with respect to the primary outcome of interest. Begg's test and the weighted regression test of Egger et al ${ }^{16}$ $(\mathrm{p}<0.05)$ were also used to assess publication bias. Potential heterogeneity in estimates of effect of $\mathrm{PO}$ versus IV hydration use across studies was explored via random-effects meta-regression analysis using the method of residual maximum likelihood (REML) to estimate the additive (between-study) component of variance $(\tau 2)$ and the proportion of between-study variance was explained with Knapp-Hartung modification. Statistical analyses were performed using Revman software V.5.2.0 and STATA, V.12, College Station, Texas, USA.

\section{RESULTS}

We obtained a total of 306 studies from the initial search and an additional 2 studies were identified through references and other sources; 160 duplicates and 139 studies which did not meet the inclusion criteria were excluded after reviewing titles and abstracts. We reviewed the full text of nine publications and five were included in the final analysis. The complete flow sheet is shown in figure 3 .

Characteristics of the studies are summarised in tables 1 and 2. Overall, the quality of the studies is low mainly due to the lack of blinding of the treatment and outcomes group (figure 1). We included 477 participants with a mean age of $64.1( \pm 10.4)$ years. Among them, $69.6 \%$ were males, $42.3 \%$ were diabetic and $63.7 \%$ had chronic kidney disease (CKD) in the analysis. Of these, 222 received IV hydration and 255 received $\mathrm{PO}$ hydration. The weighted mean baseline creatinine in the IV and $\mathrm{PO}$ arms was 1.6 and $1.5 \mathrm{mg} / \mathrm{dL}$, respectively $(\mathrm{p}=$ not significant $)$. The weighted average volume of 
Figure 1 Risk of bias

assessments for included studies.

This is the risk of bias

assessment based on author

assessment according to the

Cochrane Risk of Bias

Assessment Tool. A notation of

'+' suggests a low risk of bias; a

'-' notation suggests a high risk

of bias and a '?' notation

suggests an uncertain risk of

bias.

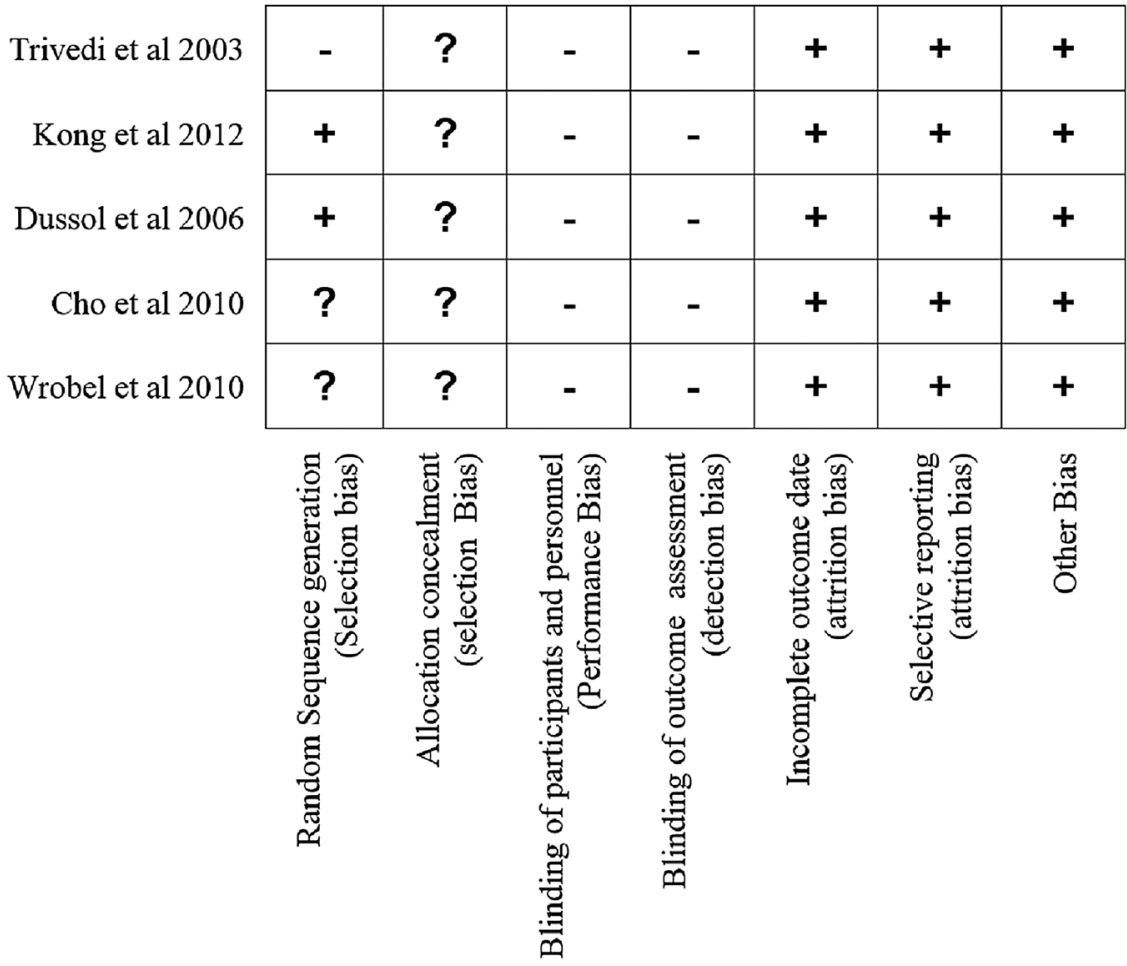

contrast used during the procedure was 134.6 and $129.7 \mathrm{~mL}$ in the IV and $\mathrm{PO}$ arms, respectively.

The incidence of CIN was $7.7 \%$ and $8.2 \%$ in the IV and PO arms, respectively, with a pooled RR of 0.97 (95\% CI 0.36 to 2.94), which was not statistically significant $\left(p=0.95 ; I^{2}=48 \%\right.$ ) (figure 4$)$. In view of the moderate heterogeneity, we conducted a subgroup analysis to examine the incidence of CIN separately in patients with CKD and normal kidney function and there was no statistical difference on either groups (figure 4). Among these, four studies with 324 patients were conducted exclusively in patients undergoing coronary procedures and there was

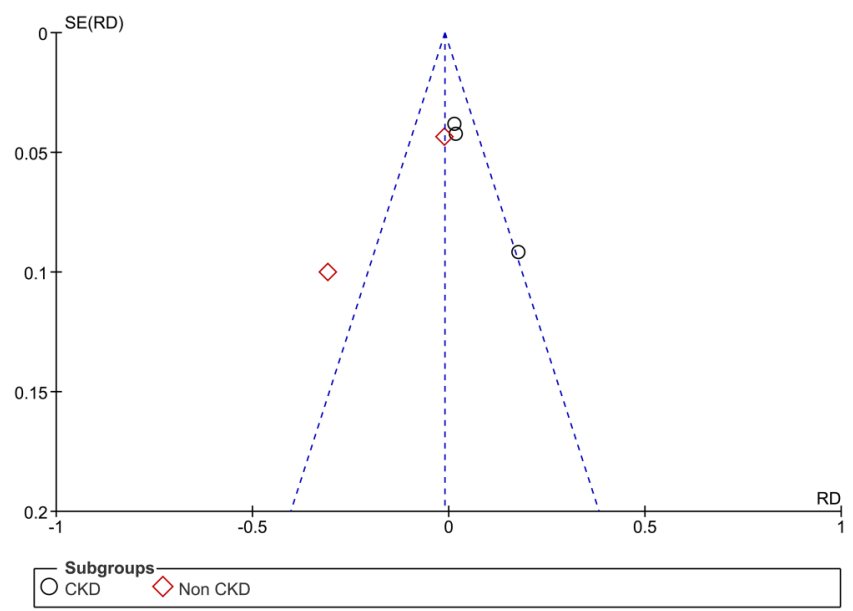

Figure 2 Funnel plot analysis of included trials. Circles indicate studies with patients with CKD. Diamonds indicate studies with patients with normal kidney function (CKD, chronic kidney disease; RD, risk difference). no significant difference in the incidence of CIN in the IV versus $\mathrm{PO}$ arm $(8.2 \%$ vs $9.6 \%$, respectively; RR 1.12 ; $95 \%$ CI 0.27 to $\left.4.8 ; \mathrm{p}=0.8 ; \mathrm{I}^{2}=60 \%\right)$. Three studies with 275 participants reported changes in serum creatinine at 48-72 h. Patients receiving PO hydration had a statistically significant lower rise in serum creatinine compared with the IV hydration group with a pooled standard mean difference (SMD) of 0.04 , (95\% CI 0.03 to 0.06 ; $\mathrm{p}<0.001 ; \mathrm{I}^{2}=62 \%$ ) (figure 5). Four studies with 428 participants reported the requirement of dialysis and no patients in either arm required dialysis after the index procedure. There appears to be no heterogeneity across studies evaluating PO versus IV hydration with respect to specific characteristics included in the meta-regression (table 3). No publication bias was found in this analysis with a bias coefficient of 0.97 (95\% CI -10.59 to 12.53 ; $\mathrm{p}=0.8$ ) (figure 2).

\section{DISCUSSION}

This meta-analysis of the RCTs demonstrates that hydration with PO fluids is as effective as hydration with IV fluids in prevention of CIN. This is important since administration of IV fluids requires hospitalisation that is economically burdensome, whereas taking PO fluids can be done at home. PO hydration is currently more relevant since most of the procedures using radiocontrast, such as CT, cardiac catheterisations, percutaneous coronary interventions and other vascular procedures by interventional radiology, are conducted on an outpatient basis. ${ }^{17} \mathrm{CKD}$ is an important risk factor for $\mathrm{CIN} ;{ }^{18}$ nevertheless, this analysis shows that PO hydration is at least as 


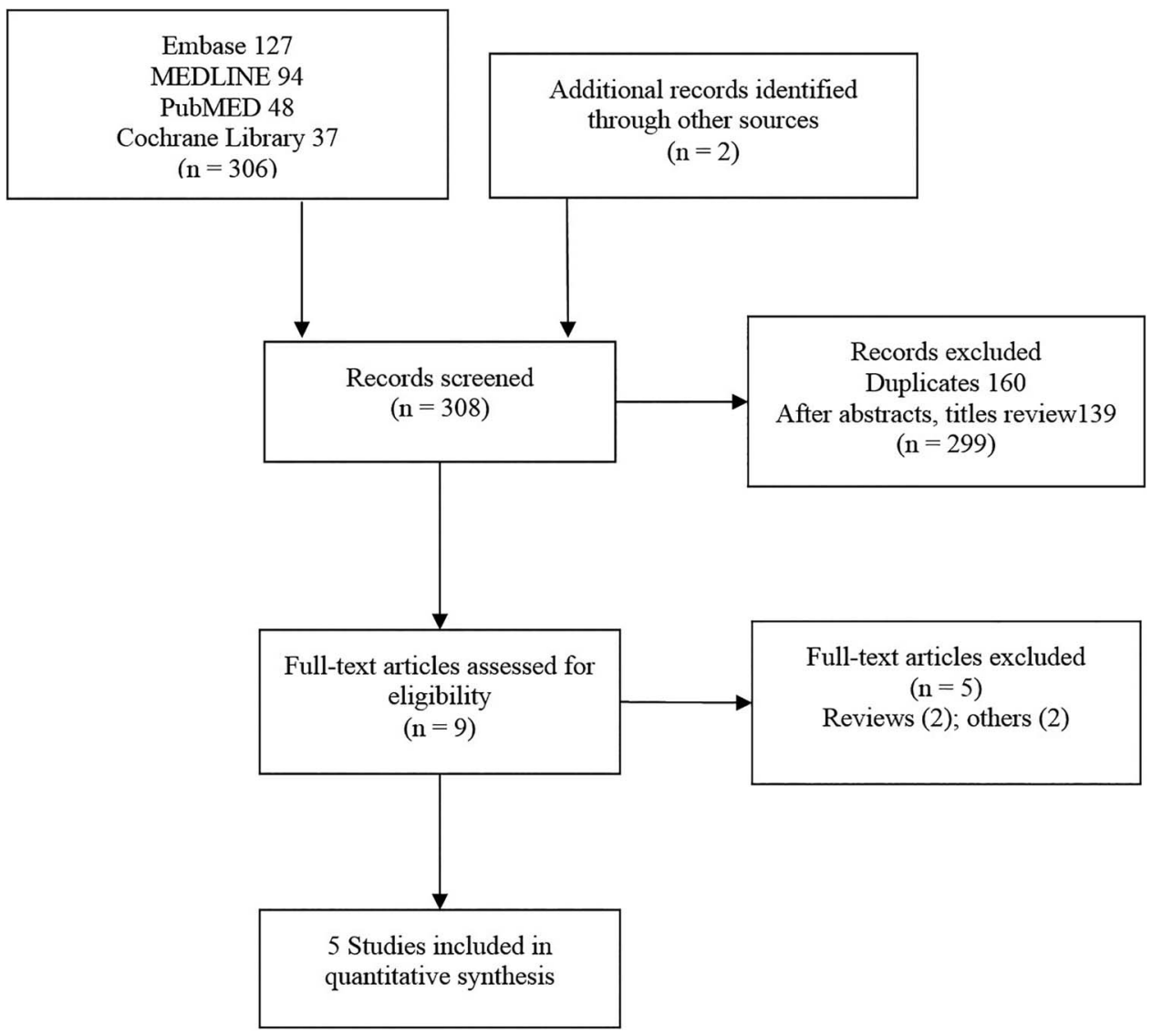

Figure 3 Flow chart for the selection of studies. Flow diagram representing the number of studies screened, reviewed and included in analysis.

effective as IV hydration in patients with both CKD and normal kidney function.

There were three trials, one with patients with $\mathrm{CKD}^{8}$ and two with normal kidney function, ${ }^{5}{ }^{11}$ which reported change in serum creatinine and were conducted exclusively on patients undergoing a coronary angiogram. These trials have shown that there was a significantly lower rise in serum creatinine in the PO hydration group compared with the IV hydration group. However, there was a significant heterogeneity among the trials and the results need to be interpreted with caution. There were insufficient data to perform a meta-regression analysis to explore the heterogeneity on the level of the reported rise in serum creatinine results in regard to baseline gender and the use of renin-angiotensin-aldosterone system (RAAS) blockade and diuretics. However, a meta-regression of these three studies including the baseline characteristics of age, history of type 2 diabetes mellitus, baseline serum creatinine and contrast volume showed no heterogeneity $(p>0.05)$. None of the patients required dialysis in either arm among the four trials reporting data on this outcome. ${ }^{5} 68{ }^{11}$ However, some studies presented data on the length of hospitalisation. Cho $e t a l^{7}$ reported no significant difference in length of hospitalisation (4.1 days in the IV arm vs 5.6 days in the PO arm).
Trivedi et a $\bar{l}$ did not report the length of hospitalisation but reported that one patient in the IV arm and three patients in the PO arm had extended hospital stay due to CIN.

The incidence of CIN in our study population is $8 \%$, which is higher than the reported incidence of $<2 \%$ in the general population but in high-risk populations with congestive heart failure, CKD, diabetes mellitus and anaemia, its incidence has been reported up to 20-30\%. ${ }^{3}$ Our study population was at a relatively increased risk compared with the general population with $42.3 \%$ with diabetes and $63.7 \%$ with CKD who are at a higher risk than the population without diabetes and normal kidney function. ${ }^{18}$ The incidence of CIN among the patients with normal renal function was $9.8 \%$ and was especially high in the $\mathrm{PO}$ hydration arm $(13.2 \%)$ which is probably skewed by the results from Trivedi $e t a l$. The reported incidence of CIN in the study was $18.9 \%$ with $34.6 \%$ in the PO hydration arm and $3.7 \%$ in the IV hydration arm. Incidentally, this is the only study included in the analysis to suggest that IV hydration is more effective than PO hydration. ${ }^{5}$ Trivedi et al acknowledge that the incidence of CIN in their study is higher than the reported incidence and the authors attribute it to sicker study population with $39-48 \%$ of patients had acute myocardial infarction and 
Table 1 Clinical scenario and hydration protocols of included trials

\begin{tabular}{|c|c|c|c|c|c|c|}
\hline Study & $\begin{array}{l}\text { Kidney } \\
\text { function }\end{array}$ & Procedure & $\begin{array}{l}\text { Contrast } \\
\text { agent }\end{array}$ & IV regimen & Oral regimen & CIN definition \\
\hline $\begin{array}{l}\text { Trivedi } \\
\text { et } a \bar{P}\end{array}$ & Normal & $\begin{array}{l}\text { Non-emergency } \\
\text { cardiac } \\
\text { catheterisation }\end{array}$ & $\begin{array}{l}\text { Low } \\
\text { osmolality, } \\
\text { ionic }\end{array}$ & $\begin{array}{l}\text { Normal saline; } 1 \mathrm{~mL} / \mathrm{kg} / \mathrm{h} \text { beginning } \\
12 \mathrm{~h} \text { before to next } 24 \mathrm{~h} \text { after the } \\
\text { procedure }\end{array}$ & Unrestricted oral fluids & $\begin{array}{l}>44.2 \mu \mathrm{mol} / \mathrm{L}(>0.5 \mathrm{mg} / \mathrm{dL}) \\
\text { absolute increase within } 48 \mathrm{~h} \\
\text { of contrast exposure }\end{array}$ \\
\hline $\begin{array}{l}\text { Kong } \\
\text { et } a l^{11}\end{array}$ & Normal & $\begin{array}{l}\text { Coronary angiogram } \\
\text { and/or angioplasty }\end{array}$ & $\begin{array}{l}\text { Low } \\
\text { osmolality, } \\
\text { ionic } \\
\text { (iopromide) }\end{array}$ & $\begin{array}{l}\text { Normal saline; } 1 \mathrm{~mL} / \mathrm{kg} / \mathrm{h} \text { beginning } \\
12 \mathrm{~h} \text { before to next } 24 \mathrm{~h} \text { after the } \\
\text { procedure }\end{array}$ & $\begin{array}{l}\text { Tap water; } 500 \mathrm{~mL} \text { within } 2 \mathrm{~h} \text { of } \\
\text { procedure and another } 2000 \mathrm{~mL} \\
\text { within } 24 \mathrm{~h} \text { after procedure or } \\
2000 \mathrm{~mL} \text { of water within } 24 \mathrm{~h} \\
\text { after procedure }\end{array}$ & $\begin{array}{l}>44.2 \mu \mathrm{mol} / \mathrm{L}(>0.5 \mathrm{mg} / \mathrm{dL}) \\
\text { absolute increase or a }>25 \% \\
\text { relative increase in serum } \\
\text { creatinine within } 48-72 \mathrm{~h} \text { of } \\
\text { contrast exposure }\end{array}$ \\
\hline $\begin{array}{l}\text { Dussol } \\
\text { et } a \hat{\beta}\end{array}$ & CKD & $\begin{array}{l}\text { Various radiological } \\
\text { procedures }\end{array}$ & $\begin{array}{l}\text { Low } \\
\text { osmolality, } \\
\text { non-ionic }\end{array}$ & $\begin{array}{l}\text { Normal saline; } 15 \mathrm{~mL} / \mathrm{kg} \text { for } 6 \mathrm{~h} \text { before } \\
\text { the procedure (no post procedure } \\
\text { hydration) }\end{array}$ & $\begin{array}{l}\text { Sodium chloride tablets; } \\
1 \mathrm{~g} / 10 \mathrm{~kg} \text { of body weight/day } \\
\text { for } 2 \text { days }\end{array}$ & $\begin{array}{l}>44.2 \mu \mathrm{mol} / \mathrm{L}(>0.5 \mathrm{mg} / \mathrm{dL}) \\
\text { absolute increase within } 48 \mathrm{~h} \\
\text { of contrast exposure }\end{array}$ \\
\hline $\begin{array}{l}\text { Cho } \\
\text { et } \mathrm{al}^{7}\end{array}$ & CKD & $\begin{array}{l}\text { Elective coronary } \\
\text { angiogram }\end{array}$ & $\begin{array}{l}\text { Low } \\
\text { osmolality, } \\
\text { non-ionic } \\
\text { (isoverol) }\end{array}$ & $\begin{array}{l}\text { Normal saline; } 3 \mathrm{~mL} / \mathrm{kg} \text { bolus over } 1 \mathrm{~h} \text {, } \\
\text { immediately prior followed by } 1 \mathrm{~mL} / \mathrm{kg} \\
\text { for } 6 \mathrm{~h} \text { after the procedure (for patients } \\
\text { greater than } 110 \mathrm{~kg} \text {, infusion rates will } \\
\text { be based on that for a } 110 \mathrm{~kg} \text { person }\end{array}$ & $\begin{array}{l}\text { Water; } 500 \mathrm{~mL} \text { started } 4 \mathrm{~h} \text { prior } \\
\text { and stopped } 2 \mathrm{~h} \text { prior to } \\
\text { procedure followed by oral } \\
\text { hydration with } 600 \mathrm{~mL} \text { of water } \\
\text { post procedure }\end{array}$ & $\begin{array}{l}>44.2 \mu \mathrm{mol} / \mathrm{L}(>0.5 \mathrm{mg} / \mathrm{dL}) \\
\text { absolute increase or a }>25 \% \\
\text { relative increase in serum } \\
\text { creatinine within } 72 \mathrm{~h} \text { of } \\
\text { contrast exposure }\end{array}$ \\
\hline $\begin{array}{l}\text { Wrobel } \\
\text { et } a \beta\end{array}$ & CKD & $\begin{array}{l}\text { Coronary angiogram } \\
\text { and/or angioplasty }\end{array}$ & $\begin{array}{l}\text { Low } \\
\text { osmolality, } \\
\text { non-ionic } \\
\text { (isoverol) }\end{array}$ & $\begin{array}{l}\text { Normal saline; } 1 \mathrm{~mL} / \mathrm{kg} / \mathrm{h} \text { beginning } \\
12 \mathrm{~h} \text { before to next } 12 \mathrm{~h} \text { after the } \\
\text { procedure (reduced to } 50 \% \text { in patients } \\
\text { with } \mathrm{CHF} \text { ) }\end{array}$ & $\begin{array}{l}\text { Mineral water; } 1 \mathrm{~mL} / \mathrm{kg} / \mathrm{h} \\
\text { beginning } 6-12 \mathrm{~h} \text { before to } 12 \mathrm{~h} \\
\text { after the procedure }\end{array}$ & $\begin{array}{l}>44.2 \mu \mathrm{mol} / \mathrm{L}(>0.5 \mathrm{mg} / \mathrm{dL}) \\
\text { absolute increase or a }>25 \% \\
\text { relative increase in serum } \\
\text { creatinine within } 72 \mathrm{~h} \text { of } \\
\text { contrast exposure }\end{array}$ \\
\hline
\end{tabular}

Table 2 Characteristics of the included randomised clinical trials

\begin{tabular}{|c|c|c|c|c|c|c|c|c|c|c|c|c|c|c|}
\hline Study & $\mathbf{n}$ & Oral (\%) & Male (\%) & $\begin{array}{l}\text { Diabetes } \\
\text { (\%) }\end{array}$ & Age IV $\pm S D$ & $\begin{array}{l}\text { Age } \\
\text { oral } \pm S D\end{array}$ & $\begin{array}{l}\text { CIN } \\
\text { oral/IV }\end{array}$ & HD & $\begin{array}{l}\text { Cr IV } \\
\text { baseline } \\
\pm \text { SD }\end{array}$ & $\begin{array}{l}\text { Cr oral } \\
\text { baseline } \pm S D\end{array}$ & $\begin{array}{l}\text { Cr IV } \\
48 h \pm S D\end{array}$ & $\begin{array}{l}\text { Cr oral } \\
48-72 h \pm S D\end{array}$ & $\begin{array}{l}\text { Contrast } \\
\text { Vol IV } \pm S D\end{array}$ & $\begin{array}{l}\text { Contrast } \\
\text { Vol oral } \pm S D\end{array}$ \\
\hline Trivedi et $a^{\Gamma}$ & 53 & $26(49.1)$ & 52 (98.1) & 10 (18.9) & $68.5 \pm 8$ & $67.2 \pm 11.2$ & $9 / 1$ & None & $1.14 \pm 0.24$ & $1.27 \pm 0.37$ & $1.27 \pm 0.48$ & $1.60 \pm 0.83$ & $201.3 \pm 92$ & $187.3 \pm 87.6$ \\
\hline Kong et $a l^{11}$ & 120 & $80(66.7)$ & $67(55.8)$ & $30(25)$ & $55.7 \pm 11.9$ & $56.05 \pm 10$ & $5 / 2$ & None & $1.15 \pm 0.29$ & $1.23 \pm 0.26$ & $1.27 \pm 0.31$ & $1.3 \pm 0.27$ & $151.2 \pm 63.1$ & $151 \pm 59.5$ \\
\hline Dussol et af & 153 & 77 (50.3) & $128(83.7)$ & $44(28.8)$ & $64 \pm 11$ & $63 \pm 15$ & $4 / 5$ & None & $2.35 \pm 0.95$ & $2.14 \pm 0.74$ & NR & NR & $115 \pm 57$ & $120 \pm 40$ \\
\hline Cho et $a l^{7}$ & 49 & $22(44.9)$ & $27(55.1)$ & $16(32.7)$ & $77.3 \pm 8.4$ & $80.8 \pm 6.5$ & $1 / 6$ & $\mathrm{NR}$ & 1.38 & 1.38 & NR & NR & 122.6 & 118.6 \\
\hline Wrobel et a $P^{\beta}$ & 102 & $50(49)$ & 58 (56.9) & $102(100)$ & $67.3 \pm 7.76$ & $63.7 \pm 7.82$ & $2 / 3$ & None & $1.24 \pm 0.45$ & $1.17 \pm 0.39$ & $1.35 \pm 0.48$ & $1.24 \pm 0.44$ & $101.1 \pm 36.6$ & $110.4 \pm 65.28$ \\
\hline
\end{tabular}

$\mathrm{CIN}$, contrast-induced nephropathy; Cr creatinine; HD, hemodialysis; IV, intravenous; n, total number of participants; NR, not reported; Vol, volume. 


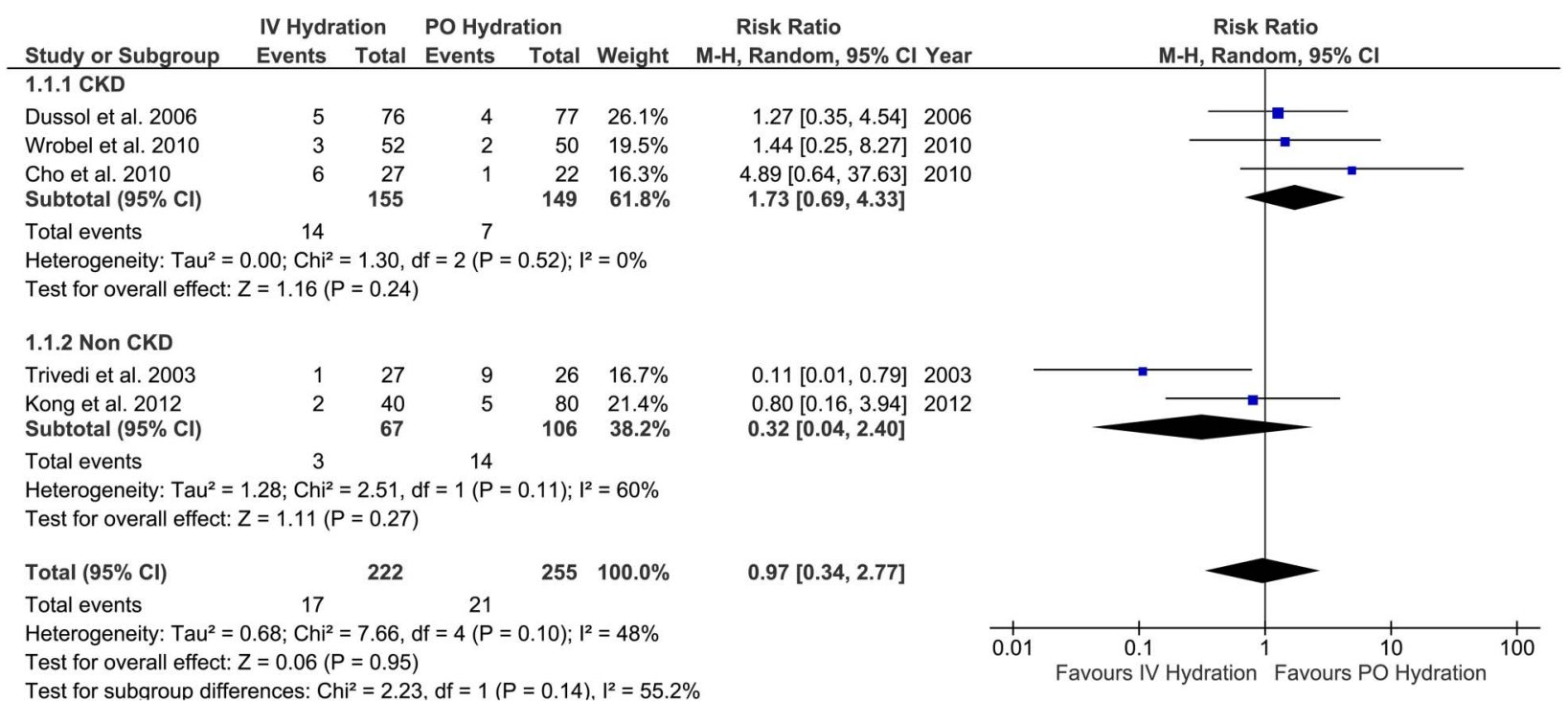

Figure 4 Incidence of contrast-induced nephropathy in patients with CKD, normal kidney function and all patients. The boxes and lines indicate the RRs and their Cls. Weights are from random-effects analysis. The size of the box indicates the relative weight of each estimate. Diamonds indicate the combined RRs (CKD, chronic kidney disease; IV, intravenous; PO, oral; RRs, relative risks).

$42-52 \%$ were admitted to intensive care unit. The PO hydration arm had unrestricted fluid access; however, the amount consumed was not recorded, so it is plausible that this group was not adequately hydrated, contributing to a higher incidence of CIN in this group. Even though there was no statistical significant difference in baseline serum creatinine between both arms, the PO arm had a higher baseline serum creatinine and wider range of distribution $(1.27 \pm 0.37)$ compared with the IV arm $(1.14 \pm 0.24)$ which could have contributed towards the higher incidence of CIN. Furthermore, the initial results could have occurred by chance in the interim analysis which may not have persisted if the trial was not terminated prematurely only after the enrolment of one-third of the expected study population.

Isotonic normal saline is known to be more protective in the prevention of CIN than an equivalent amount of hypotonic saline,${ }^{19}$ and all the trials in our analysis used normal saline for IV hydration but different regimens. Cho $e t a l^{7}$ administered a bolus of IV normal saline solution over $1 \mathrm{~h}$ prior to contrast administration, while others used a continuous regimen of IV fluids beginning $6 \mathrm{~h}^{68}$ or $12 \mathrm{~h}^{5}{ }^{11}$ prior to the procedure. The PO hydration protocol varied greatly, with no two trials having a similar PO regimen. Except for Trivedi et $a l^{5}$ who recommended unrestricted PO fluids, all other trials had prespecified outpatient PO regimens. Dussol et at ${ }^{6}$ used salt tablets $(1 \mathrm{~g} / 10 \mathrm{~kg}$ of body weight/day $)$ for $48 \mathrm{~h}$ before procedure; Wrobel et $a l^{8}$ administered mineral water $(1 \mathrm{~mL} / \mathrm{kg} / \mathrm{h})$ starting $6-12 \mathrm{~h}$ before, during and $12 \mathrm{~h}$ after procedure while Cho $e t a l^{7}$ recommended at least $1100 \mathrm{~mL}$ of regular water with $500 \mathrm{~mL}$ $4 \mathrm{~h}$ prior to and $600 \mathrm{~mL}$ after the procedure; and Kong et $a l^{11}$ recommended 2000 or $2500 \mathrm{~mL}$ of water with at least $2000 \mathrm{~mL}$ of hydration postprocedure (table 1).

\section{Comparison with other meta-analysis}

There were two meta-analyses published so far which included six trials. ${ }^{9}{ }^{10}$ Our study is more representative of a comparison of PO and IV hydration regimens since we excluded two trials as they did not meet our inclusion criteria, as the patients received additional treatments along with hydration but were included in the prior analyses. PREPARED trial ${ }^{20}$ was excluded as the PO hydration arm received additional IV hydration with half normal saline and RCT by Lawlor et $a l^{21}$ was

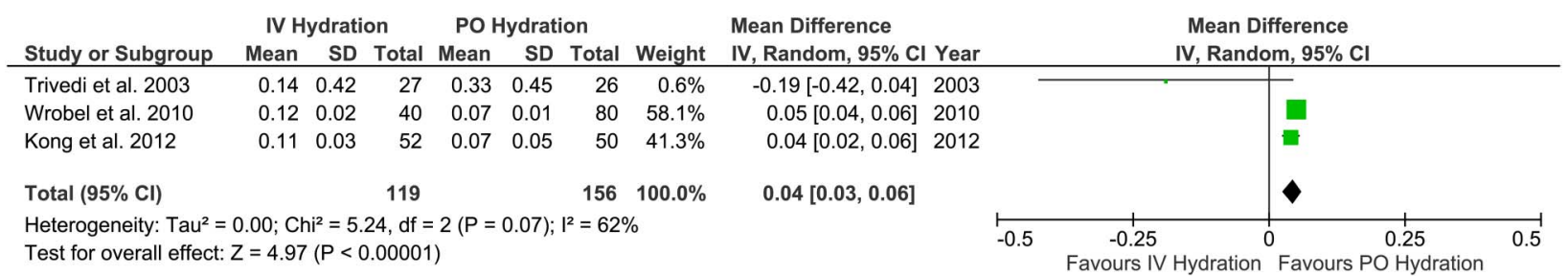

Figure 5 Standard mean difference of change in creatinine between the intravenous (IV) versus oral (PO) arm. The boxes and lines indicate the relative risks (RRs) and their Cls. Weights are from random-effects analysis. The size of the box indicates the relative weight of each estimate. Diamonds indicate the combined RRs. 
Table 3 Meta-regression of baseline characteristics of studies

\begin{tabular}{llcll}
\hline Baseline characteristics & $\mathbf{N}$ & Estimate coefficient & $\mathbf{9 5 \%} \mathbf{C l}$ & $\mathbf{p ~ V a l u e}$ \\
\hline Serum creatinine & 5 & 4.49 & -8.33 to 17.3 & 0.347 \\
Age & 5 & -0.21 & -1.08 to 0.66 & 0.497 \\
Male gender & 4 & 0.015 & -0.33 to 0.36 & 0.874 \\
DM & 5 & -0.004 & -0.39 to 0.38 & 0.977 \\
ACEi use & 4 & 0.05 & -0.29 to 0.39 & 0.574 \\
Diuretic use & 4 & 0.26 & -1.1 to 1.63 & 0.492 \\
Contrast volume & 5 & -0.09 & -0.29 to 0.12 & 0.284 \\
\hline
\end{tabular}

$95 \% \mathrm{Cl}, 95 \% \mathrm{Cl}$ of the estimate coefficient; ACEi, ACE inhibitors; DM, diabetes mellitus; $\mathrm{N}$, number of studies reporting detailed baseline characteristics.

excluded since they administered $N$-acetyl cysteine in addition to the hydration regimen. One additional randomised trial has been published since the prior meta-analysis. ${ }^{11}$ We have also performed the subgroup analysis of patients with normal kidney function and CKD at enrolment and calculated the SMD for change in creatinine along with a meta-regression to study the heterogeneity across the studies.

Hydration in general has been accepted as the cornerstone to prevent CIN; however, there is no consensus regarding the mode of administration. As illustrated in ours and prior meta-analyses, PO fluids are as effective as IV fluids. However, the data is based on only a few small studies with some inherent bias which is limiting their ability to change the practice. Hence, larger multicentre and higher quality randomised clinical trials are necessary to change the practice. In modern medicine, with an evolving number of diagnostic studies that depend on iodinated contrast along with an increasing number of complex high-risk patients, CIN is becoming a common cause of iatrogenic harm, so much so that even small improvements would lead to large reductions in CIN and thus better patient care. Similarly, costs of hospitalisations, nursing care and IV medication are increasing and since PO hydration has similar efficacy to IV fluids in preventing CIN, its wide-spread acceptance will have a greater impact on procedural costs.

\section{Limitations}

As with any meta-analysis, conclusions drawn are subject to the limitations of the original studies. Patient-level data were not available precluding subgroup analysis and the use of metaregression to evaluate the heterogeneity in baseline characteristics across the studies is not perfect and only tells us that the trend seen in outcome was irrespective statistically from the variance noted in the baseline characteristics. The evidence is based on a small number of clinical trials and patients with stages 4 and 5 CKD and left ventricular systolic dysfunction were not represented, making it less applicable to these groups. PO and IV hydration regimens were too diverse to make specific recommendations. There was significant heterogeneity among the trial, especially in calculating the SMD for change in creatinine, which was hard to explore due to the limited number of studies and reported baseline characteristics. The trials included in the analysis are of low-to-moderate quality.

\section{CONCLUSIONS}

Prophylaxis with PO hydration is at least as effective as IV hydration in preventing CIN in patients with both CKD and normal kidney function. PO hydration is cheaper and more easily administered than IV hydration, and might be more acceptable to the patients and cost-effective.

\section{Author affiliations}

${ }^{1}$ Division of Cardiovascular Diseases, Department of Medicine, University of Arkansas for Medical Sciences, Little Rock, Arkansas, USA

${ }^{2}$ Division of Cardiology, Department of Internal Medicine, Ochsner Clinic Foundation, New Orleans, Louisiana, USA

${ }^{3}$ Department of Public Health, Icahn School of Medicine at Mount Sinai, New York, New York, USA

${ }^{4}$ Division of Nephrology, Department of Medicine, Icahn School of Medicine at Mount Sinai, New York, New York, USA

${ }^{5}$ Saint Luke's Mid America Heart Institute, Kansas City, Missouri, USA ${ }^{6}$ Department of Medicine, Icahn School of Medicine at Mount Sinai,

New York, New York, USA

${ }^{7}$ Department of Public Health, New York Medical College, Valhalla, New York, USA

${ }^{8}$ Division of Rheumatology, Department of Medicine, Vanderbilt University Medical Center, Nashville, Tennessee, USA

${ }^{9}$ Department of Medicine, St Lukes Roosevelt Hospital Center at Mount Sinai, New York, New York, USA

${ }^{10}$ Division of Critical Care, Kokilaben Dhirubhai Ambani Hospital and Medical Research Institute, Mumbai, Maharashtra, India

${ }^{11}$ Division of Nephrology, Department of Internal Medicine, Ochsner Clinic

Foundation, New Orleans, Louisiana, USA

${ }^{12}$ Jackson Memorial Hospital, Miami, Florida, USA

Contributors SKA and GNN were responsible for the study concept and design; acquisition, analysis and interpretation of data; and drafting and critical revision of the manuscript for important intellectual content. SM took part in the acquisition and interpretation of data; and drafting and critical revision of the manuscript for important intellectual content. AcP participated in the acquisition of data; statistical analysis; and drafting and critical revision of the manuscript for important intellectual content. RY participated in the analysis and interpretation of data; drafting of the manuscript; and performed statistical analysis. JJD, IK, AmP, SF and PKS contributed to the drafting and critical revision of the manuscript for important intellectual content; and provided technical and material support. NA was involved in the acquisition of data; critical revision of the manuscript for important intellectual content; and provided administrative, technical and material support. SK contributed to the acquisition of data; critical revision of the manuscript for important intellectual 
content; and provided material and administrative support. GE-H participated in the drafting and critical revision of the manuscript for important intellectual content. DK and RMN contributed to the drafting and critical revision of the manuscript for important intellectual content; and provided material and administrative support. JPR contributed to the study concept and design; analysis and interpretation of data; and drafting and critical revision of the manuscript for important intellectual content. RP was responsible for the analysis and interpretation of data; and drafting and critical revision of the manuscript for important intellectual content. AMB contributed to the study concept and design; analysis and interpretation of data; drafting and critical revision of the manuscript for important intellectual content; and overall study supervision.

Competing interests None declared.

Provenance and peer review Not commissioned; externally peer reviewed.

Open Access This is an Open Access article distributed in accordance with the Creative Commons Attribution Non Commercial (CC BY-NC 4.0) license, which permits others to distribute, remix, adapt, build upon this work noncommercially, and license their derivative works on different terms, provided the original work is properly cited and the use is non-commercial. See: http:// creativecommons.org/licenses/by-nc/4.0/

\section{REFERENCES}

1. Singri N, Ahya $\mathrm{SN}$, Levin $\mathrm{ML}$. Acute renal failure. JAMA 2003;289:747-51.

2. McCullough PA, Wolyn R, Rocher LL, et al. Acute renal failure after coronary intervention: incidence, risk factors, and relationship to mortality. Am J Med 1997;103:368-75.

3. Tepel M, Aspelin P, Lameire N. Contrast-induced nephropathy: a clinical and evidence-based approach. Circulation 2006;113:1799-806.

4. Klein LW, Sheldon MW, Brinker J, et al., Interventional Committee of the Society for Cardiovascular Angiography and Interventions. The use of radiographic contrast media during $\mathrm{PCl}$ : a focused review: a position statement of the Society of Cardiovascular Angiography and Interventions. Catheter Cardiovasc Interv 2009;74:728-46.

5. Trivedi HS, Moore $\mathrm{H}$, Nasr S, et al. A randomized prospective trial to assess the role of saline hydration on the development of contrast nephrotoxicity. Nephron Clin Pract 2003;93:C29-34.

6. Dussol B, Morange S, Loundoun A, et al. A randomized trial of saline hydration to prevent contrast nephropathy in chronic renal failure patients. Nephrol Dial Transplant 2006;21:2120-6.

7. Cho R, Javed N, Traub $\mathrm{D}$, et al. Oral hydration and alkalinization is noninferior to intravenous therapy for prevention of contrast-induced nephropathy in patients with chronic kidney disease. J Interv Cardiol 2010;23:460-6.

8. Wrobel W, Sinkiewicz W, Gordon M, et al. Oral versus intravenous hydration and renal function in diabetic patients undergoing percutaneous coronary interventions. Kardiol Pol 2010;68:1015-20.

9. Cheungpasitporn W, Thongprayoon C, Brabec BA, et al. Oral hydration for prevention of contrast-induced acute kidney injury in elective radiological procedures: a systematic review and meta-analysis of randomized controlled trials. $N \mathrm{Am} \mathrm{J} \mathrm{Med} \mathrm{Sci}$ 2014;6:618-24.

10. Hiremath S, Akbari A, Shabana W, et al. Prevention of contrast-induced acute kidney injury: is simple oral hydration similar to intravenous? A systematic review of the evidence. PLOS ONE 2013;8:e60009.

11. Kong DG, Hou YF, Ma LL, et al. Comparison of oral and intravenous hydration strategies for the prevention of contrast-induced nephropathy in patients undergoing coronary angiography or angioplasty: a randomized clinical trial. Acta Cardiol 2012; 67:565-9.

12. Liberati A, Altman DG, Tetzlaff J, et al. The PRISMA statement for reporting systematic reviews and meta-analyses of studies that evaluate health care interventions: explanation and elaboration Ann Intern Med 2009;151:W65-94.

13. Higgins JP, Altman DG, Gotzsche PC, et al. The Cochrane Collaboration's tool for assessing risk of bias in randomised trials. BMJ 2011;343:d5928.

14. Higgins JP, Thompson SG. Quantifying heterogeneity in a meta-analysis. Stat Med 2002;21:1539-58.

15. Higgins JP, Thompson SG, Deeks JJ, et al. Measuring inconsistency in meta-analyses. BMJ 2003;327:557-60.

16. Egger M, Davey Smith $\mathrm{G}$, Schneider M, et al. Bias in meta-analysis detected by a simple, graphical test. BMJ 1997;315:629-34.

17. Popescu AM, Weintraub WS. Outpatient percutaneous coronary interventions: hospital and health system costs saving while maintaining patient safety. JACC Cardiovasc Interv 2010;3:1020-1.

18. Mehran R, Aymong ED, Nikolsky E, et al. A simple risk score for prediction of contrast-induced nephropathy after percutaneous coronary intervention: development and initial validation. J Am Coll Cardiol 2004;44:1393-9.

19. Weisbord SD, Palevsky PM. Prevention of contrast-induced nephropathy with volume expansion. Clin J Am Soc Nephrol 2008;3:273-80.

20. Taylor AJ, Hotchkiss D, Morse RW, et al. PREPARED: Preparation for Angiography in Renal Dysfunction: a randomized trial of inpatient vs outpatient hydration protocols for cardiac catheterization in mild-to-moderate renal dysfunction. Chest 1998;114:1570-4.

21. Lawlor DK, Moist L, DeRose G, et al. Prevention of contrast-induced nephropathy in vascular surgery patients. Ann Vasc Surg 2007;21:593-7. 